\title{
La identidad nacional a debate en el contexto de la modernidad-posmodernidad
}

María de la Luz Casas Pérez ${ }^{1}$

\section{Introducción}

$\mathrm{H}_{3}$

ace ya diez años que México se incorporó oficialmente a la modernidad.

En ceremonia celebrada el 17 de diciembre de $1992,{ }^{2}$ en la residencia oficial de Los Pinos, el presidente de México Carlos Salinas de Gortari firmaba simultáneamente con sus homólogos, el presidente George Bush Sr., de Estados Unidos, y el primer ministro de Canadá, Brian Mulroney, el texto definitivo del Tratado de Libre Comercio de América del Norte, acto con el que culminaba el periodo de negociaciones comerciales entre los gobiernos de los tres países comprometidos con dicho acuerdo. Con este simple pero significativo acto, México cruzaba el umbral de la puerta de la modernidad.

En ese momento México iniciaba un periodo de convulsiones que se reflejarían en la economía, en la política y, por supuesto, en la cultura.

Hoy, a diez años de distancia, México es otro. Por primera vez en la historia de nuestro país nos gobierna un partido diferente del PRI, se habla abiertamente de democracia y los medios de comunicación prueban las mieles de la expresión irrestricta. El Presidente de la República, el primero que, por cierto, llega al poder apoyado por una fuerte campaña mercadotécnica y publicitaria, se somete a las encuestas de popularidad para evaluar cómo está siendo percibido en las acciones de gobierno. La economía no ha mejorado mucho, como se nos prometía en 1992 cuando el Tratado de Libre Comercio de América del Norte estaba siendo negociado, ni México es más moderno que antes; por el contrario, durante el presente trabajo me propongo defender la idea de que México sigue siendo un país premoderno por sus tradiciones,

1. ITESM, campus Cuernavaca, correo electrónico: marilu.casas@itesm.mx

2. Aunque el tratado entraría en vigor oficialmente el 1 de enero de 1994, las negociaciones comenzaron poco más de dos años antes. 
que intentó ser moderno por decreto, pero que finalmente está resultando ser posmoderno por su efervescencia cultural y social.

Qué tan modernos somos, depende en gran medida de cómo nos consideremos, y en ese sentido, independientemente de las grandes campañas mediáticas que nos anuncian que vamos hacia el progreso, la realidad nos demuestra que estamos inmersos en un perpetuo forcejeo entre un pasado que nos arrastra y un futuro que nos promete. Nuestra identidad como pueblo y nuestra identidad como nación, se funden en lo que parece ser el último reducto que nos diferencia en un mundo que tiende a la globalización y a la fusión de las identidades culturales. En esta encrucijada, los medios de comunicación, portadores del discurso y actores fundamentales en la instrumentación de la mecánica del cambio, renuevan su papel de aparentes espectadores silenciosos, testigos mudos de la industrialización, de la tecnologización y de la explosión informativa, característica de cualquier sociedad moderna.

Como indica Alejandro Cruz:

En México nadie ignora que ha habido un cambio histórico, un cambio político, con mayúscula, que llevó a un candidato opositor al gobierno nacional y que, por lo mismo, modificó la distribución del poder político en el país. Sin embargo, ¿qué ha pasado con los cambios que se supone traería el Cambio? ${ }^{3}$

Hay que recordar que el cambio está estrechamente relacionado con la idea de modernidad. El hombre de la modernidad añora el progreso, porque es a partir de éste que se le plantean las promesas de un futuro que resuelve todas las inequidades y aligera todas las cargas.

Y fueron precisamente los medios de comunicación los que ayudaron a generar el imaginario del cambio y a gestar en la ciudadanía la idea de que un futuro mejor era posible.

Sin demeritar con esto el tortuoso camino que ha llevado a nuestro país a la tan ansiada transición democrática, sí es menester aquí señalar que los medios de comunicación han sido consustanciales en la difusión de un imaginario que permitiera precisamente el tránsito hacia la modernidad. Nada más que en el proceso de reflejar la realidad, los medios terminaron proyectando a un país complejo y caótico que poco o nada se parece al discurso modernizador proveniente del poder político que prometía el mejoramiento de los niveles de vida de la ciudadanía.

¿Cuáles son, sin embargo, los nexos que conectan el discurso de la modernidad, con el de la identidad, no nacional sino cultural de los pueblos, y con el proyecto globalizador que circula libremente a través de los medios de comunicación? ¿Cómo es que el Estado articula los mecanismos de modern-

3. Cruz, Alejandro (2001), "Los cambios del cambio", en Nexos, julio, p. 54. 
ización y los da a conocer, sin aparente contradicción con los intereses de los movimientos y de los sujetos sociales, y en consonancia con una utopía alcanzable para todos? Esa es la temática que intentaré explorar en las próximas páginas.

\section{Modernidad e identidad nacional}

¿Qué es la modernidad, sino un recurso de la razón para crear la ilusión humana de haber alcanzado un estado de avance? ¿Qué es la historia, sino un recurso del hombre para explicar su tránsito por las distintas etapas de su evolución, a las que ha dado burdamente en calificar de premodernas, modernas y ahora posmodernas? ¿Qué es la modernidad, sino un escurridizo precepto conceptual que utilizamos a voluntad para exigir derechos y evadir

responsabilidades?

La modernidad es producto de la racionalidad humana, escollo filosófico e intelectual que garantiza racionalmente la explicación de un estadio en que el hombre deviene distinto de sí mismo, originador de procesos y de relaciones; la modernidad viene siendo hija natural del Siglo de las Luces, producto de la secularización de la vida cotidiana y del momento en que la racionalidad toma las riendas de la existencia humana, para declararse única e incuestionable controladora de los destinos de las sociedades y de las naciones. A bordo de la razón, el hombre deja atrás los nubarrones negros de las sociedades tradicionales y primitivas en las que su destino era determinado por fuerzas oscuras, e iluminado por un panorama espiritual prometedor plagado de destellos contractualistas, se obliga a navegar en las aguas de la modernidad, guiado por el faro del progreso.

$\mathrm{Si}$ hemos de intentar descubrir qué es eso que hoy llamamos modernidad, quizás nos sea de suma utilidad recordar las palabras de Marshall Berman en su Brindis por la modernidad, cuando dice:

Todos los hombres y mujeres del mundo comparten hoy una forma de experiencia vital -experiencia del espacio y el tiempo del ser y de los otros, de las posibilidades y los peligros de la vida- a la que llamaré modernidad. Ser modernos es encontrarnos en un medio ambiente que nos promete aventura, poder, alegría, crecimiento, tránsformación de nosotros mismos y del mundo y que al mismo tiempo amenaza con destruir todo lo que tenemos, todo lo que sabemos, lo que somos. Los ambientes y las experiencias modernas cruzan todas las fronteras de la geografía y la etnicidad, de las clases y la nacionalidad, de la religión y la ideología: en este sentido, puede decirse que la modernidad une a toda la humanidad. No obstante esta unión es paradójica, es una unión de la desunión: nos arroja a un remolino de desintegración y renovación perpetuas, de conflicto 
y de contradicción, de ambigüedad y angustia. Ser modernos es ser parte de un . universo en el que, como dijo Marx, "todo lo que es sólido se evapora en el aire". 4

¿Es éste un remolino en el que nos encontramos inmersos, prácticamente sin salida? ¿Será la condición moderna un estadio obligado del hombre en su permanente búsqueda por una noción utópica de progreso? El progreso, concebido como avance, condición de movilización de las sociedades humanas, implica, como indica Berman, transformación, aventura y crecimiento. Preconiza salud, felicidad y mejoramiento, y sin embargo, llega no pausada y placenteramente sino con súbitos y dolorosos quebrantamientos. Modernidad, crisis y progreso son los términos de la ecuación que distinguen a nuestro tiempo (Subirats en Casullo, 1989: 218).

Cada sociedad busca poner en marcha sus procesos de modernización, en el afán de desarrollar su propia ecuación de modernidad, crisis y progreso; el problema es que dichos procesos de modernización, en la era contemporánea, se encuentran supeditados no sólo a los impulsos modernizadores propios de cada contexto social, sino a los avatares de un contexto globalizador internacional que obliga a las sociedades menos modernas a seguir ritmos modernizadores exógenos a sus patrones originales de desarrollo.

Así por ejemplo, nuestras sociedades latinoamericanas, desde su gestación como naciones, se sintieron condicionadas a voltear la mirada a Europa y a seguir sus patrones de modernidad y de progreso, y en la era moderna, ahora que ya hemos avanzado y nos hemos modernizado, volteamos hacia nuevas fórmulas utópicas de modernidad, que tal y como nos plantea la nueva condición moderna, representan un avance respecto de etapas anteriores. De tal suerte que, según José Joaquín Brunner (1990), América Latina en su desarrollo contemporáneo, experimenta una serie de procesos contradictorios y heterogéneos de conformación de una modernidad tardía, construida en condiciones de acelerada internacionalización de los mercados a nivel mundial. En otras palabras, iserá que la corriente de modernidad nos lleva inexorablemente hacia algún destino al que necesariamente tenemos que arribar, y al que nos hemos incorporado tardíamente? ¿Hemos llegado tarde al festín de la modernidad, como indicaba Octavio Paz? ¿Deseamos llegar? ¿O será que hacemos esfuerzos por resistir nuestra incorporación al bloque internacional de la modernidad? Quizás sea por ello que los procesos modernizadores latinoamericanos se encuentran especialmente cargados de brotes violentos y desgarradores. Carlos Fuentes (1990: 10-11) ha apuntado al respecto que somos un continente en búsqueda desesperada de su modernidad, pero demasiadas veces hemos reaccionado violentamente contra seme-

4. Berman, Marshall, "Brindis por la modernidad", en Casullo, Nicolás (comp.) (1989), El debate modernidad-posmodernidad, Editorial Puntosur, p. 67. 
jante búsqueda, haciendo intentos por regresar a nuestro pasado tradicional. Esto nos lleva a considerar que América Latina, sin embargo, y muy a su pesar, se encuentra encadenada de mil maneras a la modernidad (Brunner: 1992: 29).

Nuestro país viene haciendo súbitos y dolorosos intentos por acercarse a la modernidad; y en el proceso ha dejado de lado importantes elementos para el desarrollo social que se manifiestan en pobreza, desarraigo, marginación y, en general, nuevas formas de intolerancia y de disidencia debidas al acelerado impulso modernizador al que nos ha obligado el Estado.

Esta modernidad, que se derrama como un alud incontenible, aparece acompañada de la imagen o convencimiento de que los elementos positivos de la misma serán mayores que los negativos; que el progreso implacable hasta derramará su cadena benéfica de forma irrefrenable sobre la sociedad mexicana en forma total, asistiéndose a un verdadero "despegue social y político". 5

En su camino a la modernidad, México ha intentado varios acercamientos, ha puesto en marcha distintos procesos modernizadores. Durante la posguerra y específicamente a partir de la etapa de crecimiento con estabilidad, el país buscó impulsar la planta productiva y generar un sentimiento nacionalista que permitiera a las fuerzas sociales asumir la bandera del progreso como la única alternativa para lograr la estabilidad política y social. Ya hacia finales del siglo XX y convencido de que México no podía sustraerse a los impulsos globalizadores de la economía internacional, el Estado buscó el camino rápido de la modernización económica a través de nuestra entrada a la Comunidad Económica de América del Norte, a través de la firma del Tratado Trilateral de Libre Comercio con Estados Unidos y Canadá. Sin embargo, como indica Huntington, hay que tener cuidado en creer que porque una sociedad ha puesto en marcha procesos de modernización, que producen efectos políticos relacionados con la modernización social, cultural y económica, se ha logrado la transición de un Estado tradicional a uno moderno.

Dice Huntington:

En la práctica, la modernización siempre lleva implícito un cambio en un sistema político tradicional, y por lo general su desintegración, pero no necesariamente un avance significativo hacia un sistema político moderno. ${ }^{6}$

En parte eso fue exactamente lo que sucedió. El régimen o sistema de partido imperante se resquebrajó. El proceso de modernización económica

5. Fernández Reyes, Otto (1993), "El dilema de la modernidad", en el suplemento especial de política El Nacional, 28 de enero, p. 10.

6. Huntington, Samuel (1972), El orden politico en las sociedades en cambio, Buenos Aires, Paidós, citado por Fernández Reyes, Otto, op. cit., p. 10. 
fue tan acelerado que impactó negativamente la estabilidad de los estamentos políticos tradicionales que sostenían al sistema social. Y no sólo se presentó una fractura en el sistema político sino también en el dispositivo simbólico aglutinador de la unidad de la nación (Constantino Toto, 2000; en Judit Bokser, 2000: 76-81).

La modernización impuesta desde arriba generó, pues, un proceso de deterioro que promovió un retroceso hacia comportamientos premodernos en muchos ámbitos, y en muchos casos incluido el político. Pese al aparente éxito del proceso de apertura y participación ciudadana y a la llegada del tránsito hacia la democracia, en realidad observamos un debilitamiento correlativo de las formas tradicionales de representación política; expresa la decadencia de las ideologías políticas y de la capacidad de representación del conjunto de la vida social por parte de los actores políticos (Touraine, 1992), lo cual se tradujo en una dependencia mucho mayor de los mecanismos aglutinadores de la conciencia social y de sus estrategias, es decir de los medios de comunicación.

Un proceso de modernización integral hubiese implicado como correlato indispensable mecanismos modernizadores igualmente importantes en la arena social, sin embargo, al vigilar y proteger todos los aspectos de la vida económica y luego impulsar a la economía bruscamente hacia la apertura el Estado mexicano, rompió con la identidad tradicional entre las esferas de la política y la economía.

En sentido estricto, nos referimos aquí a las formas de modernización que habían asignado al Estado un papel como garante del desarrollo y la modernidad, así como de salvaguarda de intereses e identidad de "todos" los sectores sociales. Se trataba de una identidad conveniente y estable para el sistema político, el cual absorbía las tensiones de una esfera remitiéndolas a la otra (Fernández Reyes, 1993: 10).

De pronto, los mecanismos modernizadores giraron 180 grados para proponer la desestabilización, desconcentración, descentralización y liberación económica en medio de una situación particularmente incierta políticamente.

La transición comenzó de manera abrupta en julio de 1988, una transición que, de acuerdo con Antonio Camou, continúa irresuelta hasta la fecha (1992: 57). Este autor indica que, cuando el régimen-sistema político mexicano ya estaba en transformación, el proceso transicional del régimen-sistema se intentaba orientar en términos de una democratización política en sentido amplio, pero mostraba todavía importantes retrocesos de carácter autoritario. Cada vez que el viejo régimen quería hacer notar sus intenciones de hacer acompañar a la modernización económica de una modernización política, salían a flote los fraudes, las violaciones a los derechos humanos y la poca disposición del régimen para honrar su palabra. 
La modernización debe ser un proceso - de ahí que hayamos hablado, desde hace tiempo, de las paradojas de la modernización- que necesariamente vaya hacia atrás, para recoger lo que se perdió o simplemente se ha debilitado y vaya también hacia delante, para atender rezagos que ya están, y para anticipar el futuro. ${ }^{7}$

Las voces que indican que el Partido Revolucionario Institucional careció de visión para cambiar y que por ello perdió el poder, pierden de vista que el cambio lo inició precisamente el PRI al forzar la modernización económica por decreto, pero que descuidó la multiplicación de las expectativas sociales. En realidad lo que se generó fue una asimetría entre la capacidad institucional para traducir expectativas de sectores sociales cada vez más amplios y diferenciados alrededor de nuevos movimientos sociales y organizaciones no gubernamentales. Al no tener el sistema la capacidad de atender políticamente a las nuevas clases que el cambio económico alentó, el sistema perdió sustento. Los medios de comunicación tomaron las riendas por encima de las estructuras del poder establecido y se dedicaron a azuzar el descontento. Su ventaja se vio incrementada por la crisis de la política y lo político en el contexto social. La existencia de divisiones sociales abandonadas o relegadas a un segundo plano por el sistema político (tanto en el plano de gestión como en el del poder), favoreció el surgimiento de temas sociales pertinentes y estructurados alrededor del principio de inckisión en la lógica discursiva del sistema político.

Ahora bien, lo anterior resulta increíble, siendo que la modernización del partido en el poder fue desde siempre una reiterada aspiración del PRI a raíz de las numerosas crisis económicas que vivió nuestro país. Ya desde 1990 el entonces presidente del partido Francisco Ruiz Massieu discutía la pérdida relativa de la capacidad de transformación del PRI frente a otras instituciones políticas, y la necesidad del desarrollo de una sociedad más plural, descentralizada, analítica, informada y crítica (Ruiz Massieu, 1990: 30). Lo anterior dio como resultado que el propio presidente Carlos Salinas de Gortari indicara en su momento:

La modernización del PRI es una tarea colectiva. Cambiaremos, pero para fortalecernos. Cambiaremos, sí, pero no a costa de nuestra fuerza electoral y de nuestra unidad interna, garantías de avance democrático y revolucionario para el país. ${ }^{8}$

Para demostrar que el partido tenía verdaderas intenciones de llevar a cabo la modernización del sistema, era necesario asegurar el poder a costa de

7. Ruiz Massieu, José Francisco (1990), Ideas a tiempo, Editorial Diana, p. 31.

8. Salinas de Gortari, Carlos (citado como preámbulo al capítulo sobre el PRI), en Ruiz Massieu, José Francisco, Ideas a tiempo, op. cit., p. 22. 
lo que fuera. Las declaraciones del Presidente dictaron entonces las acciones a tomar por parte de la clase política en el poder; un hecho significativo terminó por concretar la dirección del proceso modernizador en marcha:

En diciembre de 1991, el gobierno mexicano calladamente incendió las boletas electorales de las elecciones presidenciales de 1998. Este acto, que aseguraba que ningún gobierno posterior pudiera probar la naturaleza fraudulenta de la elección de Carlos Salinas de Gortari, fue el intento de cerrar la puerta al pasado. En la recta final para la culminación de un Tratado de Libre Comercio para América del Norte (TLC), resultaba crucial que ningún gobierno mexicano pudiera probar qué tanto engaño y fraude se había requerido para poner en marcha la posibilidad de un libre comercio con Estados Unidos. ${ }^{9}$

Y es que, si así se quiere, se pretendía consumar la ruptura de una antigua modernidad (Fernández Reyes, 1993: 11), una modernidad que dictaba los designios del próximo Presidente de la República entre bambalinas y un proceso que se había adelantado a su tiempo.

La dirección, en términos de política modernizadora, estaba dada desde principios de la década de 1980, en que la reestructuración capitalista internacional había iniciado el movimiento de la liberalización e integración de los mercados; lo que hacía falta era dar los pasos firmes para el proyecto de transformación social, incluida la transformación política. Según indica Otto Fernández Reyes, la naturaleza de los tradicionales mecanismos de cooptación, mediación y representación sufrieron en ese momento una modificación sustancial (Fernández Reyes, 1993: 13). Las elecciones de 1988 representaron un parteaguas, proyectando un panorama ejemplar de acción cívica poniendo en entredicho los cimientos sobre los que se sustentaba la modernización autoritaria, sin llegar a escindir, sin embargo, el alcance de los cambios estructurales propuestos por la clase política dominante. Sin embargo, no lograron aminorar los destinos que para México ya se encontraban trazados.

Hoy en día, esa clase política ya no está en el poder. Tardíamente se percató de que si bien los cambios económicos se inducen, los cambios políticos llevan su propia lógica y tienen sus propios tiempos. Hoy, la clase gobernante que desarrolla los cambios está teniendo fuertes problemas para articular nuevas estructuras de acción sobre la base de los viejos andamiajes políticos. Ha continuado sobre el camino de la modernización económica, pero ha tenido que sujetarse a las exigencias de los nuevos actores políticos, por lo que ni siquiera ha podido concretar los cambios que se esperaban cuando se firmó el TLC.

9. Traynor, Ken, "The Origins of Free Trade Mania. The People of Mexico and Canada does not Want Free Trade, But Big Business Does; and Big Business Gets What it Wants", en Jim Sinclair (editor) (1992), Canada and Free Trade with Mexico. Crossing the Line, Vancouver, New Star Books, p. 2. 
Si bien la economía mexicana no se encuentra en un periodo agudo de crisis como aquellas que sufrió en décadas pasadas, tampoco el bienestar, el progreso y la modernidad sugeridos por nuestra entrada al bloque económico de América del Norte han traído los beneficios esperados por la población. Por el contrario, ahora estancada, la economía mexicana corre el riesgo de registrar un menor crecimiento. Esta situación se debe en parte al desempeño de la economía estadounidense que enfrenta su primera desaceleración después de diez años, motivada por los actos terroristas del 11 de septiembre de 2001. Es la primera vez que México vive un ciclo económico a la baja desde nuestra entrada al TLC.

Por otro lado, inmersa en la inercia de los cambios y aparentemente apoyada por una tendencia internacional que le sugiere el no retorno a las estructuras económicas anteriores, la nueva clase política gobernante se asume como la depositaria de la transición política, y como aquella que resolverá sin ningún problema los cauces de la nueva modernidad necesaria para el México del nuevo milenio.

Impuesta desde arriba y autoritariamente, la modernización se presenta como una destrucción y una caída para los más, como una edad de oro de progreso y poder para los menos. A esta sociedad desde siempre dual y desgarrada se la quiere una vez más dividir en dos sociedades, la de los incluidos y la de los excluidos, la de los establecidos y la de los nomás acampados, según la moderna sociedad dual que la actual reestructuración mundial del capitalismo quiere imponer en todos los países... ${ }^{10}$

Resulta connatural para muchos pensar en que cualquier proyecto modernizador, aun cuando sea específico, implica una reestructuración a muchos niveles de todas las esferas que conforman parte de la vida social, la política, la economía, la cultura. El movimiento brusco de una de las esferas, necesariamente afecta a las demás. Los mercados económicos traen consigo la posibilidad de consumir nuevas mercancías, el consumo de productos conlleva nuevos patrones de vida, los sectores sociales se recomponen, $o$, dicho de otra manera, la modernización enfrenta formas nuevas y viejas de reconstitución de la movilización y subjetivización de los actores y sujetos sociales (Fernández Reyes, 1993: 10).

Por un lado, los Estados nacionales establecen programas de modernización que imprimen dirección a las políticas modernizadoras, y por otro los mecanismos instrumentales de la modernidad se ponen en operación para permitir la transformación de la sociedad; en este sentido comulgamos con Touraine, quien insiste en la necesidad de separar la modernidad como objetivo, de la modernización como mecanismo (Touraine, 1990: 3-19).

10. Gilly, Adolfo (1988), "La otra modernidad", en Nexos, núm. 124, abril, p. 33. 
Por otro lado, en el caso de México descartamos la presencia de una modernización endógena al todo social, que se manifiesta con factores de cambio internos, pero también bajo presiones muy fuertes del exterior, de manera que estamos ante visiones alternativas de continuidad y escisión que permean los ámbitos tanto de lo político, lo económico y lo social como de lo cultural.

No es gratuito que el nuevo gobierno esté experimentando desajustes en las estructuras sociales que alimentaban y sostenían estable al sistema económico. Las clases campesinas, obreras y populares que anteriormente se mantenían cooptadas en permanente adhesión y lealtad al PRI, están exigiendo su parte del beneficio de la modernidad y del cambio prometido. Sus manifestaciones han sido por demás coloridas y multivariadas: desde las manifestaciones en la desnudez de los miembros de la clase magisterial, hasta el golpear de machetes por parte de los ejidatarios de San Salvador Atenco. De todo ello han dado cuenta los medios de comunicación. Paralelamente, las clases medias se contentan con entrar al juego de la participación cívica a través de la encuesta telefónica o del plebiscito para la consulta de la acción política. En todos los casos, en un ejercicio de poca práctica y experiencia de comunicación política, el nuevo gobierno ha tenido que reaccionar, y a veces sobrereaccionar ante las demandas sociales.

La cultura, por lo menos en Latinoamérica, dice Brunner, y ciertamente en México, añadiríamos nosotros, está en pleno proceso de incorporarse a la modernidad (especialmente en la medida que los medios de comunicación la absorben, difundiendo continuamente sus promesas de felicidad a través del consumo), para transformarse en el vehículo multiforme de una creciente integración de masas (Brunner, 1990: 38).

A diez años de distancia, México es hoy muy diferente de lo que fue en 1992, cuando nuestro país estaba entrando al proceso de negociación del TLC. Los medios de comunicación han incrementado su importancia y su participación, no sólo en la oferta cultural y de consumo, sino también en el discurso de la participación política. Han incrementado su nivel de crítica ante el gobierno de transición, recordándole insistentemente las expectativas no cumplidas; ofrecen reportar las dimensiones del cambio y exigen no solamente coadyuvar a la participación ciudadana, sino también involucrarse directamente en la toma de decisiones.

A diferencia de otras épocas, hoy los medios de comunicación cuestionan la palabra del Presidente, le recuerdan el porcentaje de votos que aprueban o no aprueban su actuación, reportan el caos político, la pérdida de liderazgo y los riesgos de ingobernabilidad que se manifiestan en el Congreso y cuestionan los mecanismos de comunicación directa del jefe del Ejecutivo con la ciudadanía. 
Mientras tanto, junto con la transición política estamos sufriendo una transición cultural; nuestra identidad como mexicanos está en transformación. Hoy la Iglesia no está ya separada del Estado, sino que se involucra abiertamente con la crítica en el ejercicio de gobierno, la educación formal ha perdido terreno respecto de los medios de comunicación y éstos, abriendo sus puertas a todo tipo de voces, han incluido en su programación incluso aquellas manifestaciones que como el Big Brother traspasaron la delgada línea de la vida privada y nos recuerdan que la esfera de lo público también es víctima del cambio.

Afortunadamente, una sociedad moderna, que integra fenómenos de industrialización, de productividad y de informatización a escala global, no puede prescindir de la presencia de ciertas fuerzas sociales e intelectuales que a través de una importante imaginación señalen los efectos devastadores del progreso. Uno de ellos, quizás el más trascendente en términos de que corre el riesgo de minar el último reducto que nos separa de la integración absoluta de los mercados internacionales, es el de la cultura. Ya desde 1991 Javier Esteinou indicaba:

Tradicionalmente, la construcción del modelo de país que hemos deseado ser en las últimas cinco décadas se ha fundado, en primer término, desde la instancia económica; en segundo término desde la fase política; y casi nunca se ha elaborado desde nuestro nivel cultural de la sociedad. ${ }^{11}$

Ello se debe, quizás, a que no hemos alcanzado ser modernos en el renglón cultural, ya que, como dice Brunner, no existe modernidad allá donde los consumidores (de los productos culturales) no alcanzan un cierto grado de autoniomía local, y cuando no existe una cultura nacional capaz de expresar la modernidad (Brunner, 1990: 23).

Esto querría decir que para ser modernos culturalmente deberíamos poder producir y defender nuestra propia cultura, cuando una de las características más importantes del hombre moderno, tal y como filosóficamente se le describe, es la posibilidad de reflexión del sujeto, que a su vez lo posibilita para expresarse y aceptar la pluralidad de los discursos, e incluso generar acción y participar como sujeto político.

Resulta increíble pensar que la modernidad haya dejado de lado la esfera cultural, y que el Estado mexicano no haya contemplado mecanismos modernizadores de la cultura, cuando:

11. Esteinou, Javier (1991), "La televisión mexicana ante el modelo de desarrollo neoliberal", Fundación Manuel Buendía, Programa Cultural de las Fronteras, p. 11. 
Con ello, al considerar la cultura como elemento de lujo se ha ignorado que los proyectos de desarrollo nacional sólo tienen sentido, o no lo tienen, si son expresiones de un proyecto cultural. Hay que considerar que no hay desarrollo en abstracto. El crecimiento y la transformación de los grupos humanos concretos siempre se dan en función de una historia, un presente y un futuro deseable, a partir de su propia peculiar visión del mundo, de su sistema de valores, de sus conocimientos y formas de organización, de sus deseos y esperanzas; en fin, de su cultura. Por ello, "la cultura no es una dimensión o un elemento más del desarrollo sino el marco general en el que éste se ejecuta, y por el cual, se realiza. En síntesis, la 'cultura' le da al proyecto nacional su razón de ser. ${ }^{12}$

Sin embargo, la modernidad, como indica Brunner, significa cosas bien distintas: significa que los procesos de comunicación se masifiquen a través del mercado; que el consumo simbólico esté articulado a procesos formativos organizados para toda la población; que el uso de conocimientos e información vincule de un modo cada vez más central las distintas esferas separadas de la sociedad: la producción económica con la política y a ésta, como vehículo de hegemonías, con el mercado. No es extraño entonces, que la arena de la cultura, fuera de la modernización económica y de la supuesta modernización política, haya sido aparentemente dejada de lado, cuando en esencia ha sido la primera en participar del proceso, ya que de hecho, la globalización de los mercados culturales se mueve por delante de la globalización de los mercados económicos y de la política (Brunner, 1990: 23).

Lamentablemente, como indicaba Octavio Paz, la modernidad "cortada del pasado y lanzada hacia un futuro siempre inasible, vive al día: no puede volver a sus principios y así, recobrar sus poderes de renovación" (Paz, 1967: 170). De manera que la modernidad siempre etérea y joven se encuentra en permanente conflicto con la cultura, que insiste en recordarle elementos de su pasado, en cuestionar sus visiones de futuro, y por lo mismo, amenaza con poner en riesgo los avances propuestos por la modernidad.

En México coexisten fuerzas que arrojan a nuestro país hacia la modernidad, con otras que le anclan a un pasado tradicional esencial. La vida acomodada de las élites, la ropa de marca y los almacenes de las grandes firmas internacionales coexisten con la pobreza, el hambre, la miseria y la marginación. Dichas fuerzas son impulsadas a través de diversos mecanismos modernizadores que funcionan como instrumentos de respuesta ante dos elementos que son consustanciales a la modernidad: la continua complejización de las demandas sociales y la incertidumbre.

12. Haza Remus, Luis Armando (1988), "Políticas de financiamiento de la cultura". Seminario de Política Cultural en México, Coordinación de Humanidades, Centro de Investigaciones Interdisciplinarias, Universidad Nacional Autónoma de México, 8 de noviembre, citado por: Esteinou, Javier, op. cit., p. 12. 
La modernización, ese movimiento a cuya cabeza se encuentra el Estado, resulta ser la herramienta que rearticula las diversas demandas y las distintas respuestas, abre y cierra las válvulas de escape y dirige las fuerzas sociales en la dirección programada. Empero, aunque la dirección pueda estar trazada, no todos los mecanismos operan con la misma fuerza y con el mismo empuje. Así, por un lado, en nuestro país la modernización económica, impulsada abruptamente y con tiempos de respuestas establecidos internacionalmente, ha sido una modernización autoritaria; la modernización política, aunque marcada por sus propios tiempos y sus propios desafíos, se encuentra en transición, pero más que para incorporar y dar voz a nuevos actores políticos al proyecto de modernidad, para conducir a la sociedad mexicana a un relanzamiento pleno del mercado y de las clases dominantes a ejercer una total hegemonía estatal con tintes democratizadores, por lo que en ese sentido ha quedado rezagada, y aunque el Estado mexicano se empeñe en demostrar en todos los foros internacionales que México es finalmente una democracia, las formas de premodernidad política de grupos presión, sindicatos e incluso de algunos partidos, insisten en recordarnos que estamos anclados a viejas prácticas corporativistas que nos impiden nuestra liberación cívica.

Por lo que respecta a la arena cultural, ésta es la más acelerada de todas, ya que lejos de asumirnos estables en la aceptación de una modernidad cultural que implicaría una apropiación del producto cultural y de la aceptación de la pluralidad, hemos eclipsado socialmente el momento moderno y súbitamente hemos pasado al instante efímero de la masificación de los discursos y la generación de imaginarios colectivos de progreso a la ilusión del acercamiento a la inserción de México a la sociedad digital, del servicio público a través del ciberespacio y de la participación ciudadana que se registra instantáneamente mediante los portales de Internet. En suma, intentamos acercarnos a la sociedad transparente de la información, cuando que todavía en algunas comunidades ni siquiera se cuenta con energía eléctrica y por tanto no existen para el nuevo mundo digital. Así, nos encontramos en una realidad en la que conviven algunos elementos y valores tradicionales, por lo que nos hemos convertido en culturalmente posmodernos.

\section{Identidad cultural y fusión posmoderna}

En la frenética variedad del mundo moderno aparece de pronto, con r. ra insistencia, el tema de la identidad. Como si el desacostumbrado número de las opciones que se nos ofrece recordara a nuestra alma que, en ocasiones, la abundancia va de la mano de la desintegración, y requiriéramos entonces un escudo que preservara nuestra memoria, las hazañas realizadas por nuestros 
ancestros, evitando el olvido de las obras del ingenio humano que confieren el sentido de pertenencia y nos llevan a admirar la región o nación de nuestro destino. ${ }^{13}$

Uno de los elementos que hemos introducido aquí como correlato de la modernidad, es la identidad nacional. Es la identidad, primero cultural y luego nacional, la que nos define como sustancialmente diferentes dentro del torrente de la modernidad.

Aun cuando la modernidad sea un punto de luz al otro lado de la orilla, y diversos sean los mecanismos modernizadores que tiendan a llevarnos hacia ella, hay instantes en los que nos interesa, nos es esencial voltear la mirada hacia el punto de partida. Son constantes, por tanto, las referencias hacia el tema de la identidad, entendida como la necesidad social de no diluirse en el proceso, y la conveniencia política de identificar a la nación con el proyecto modernizador.

A lo largo de nuestra historia, en México ha habido numerosas discusiones en torno al tema de la identidad nacional, particularmente en periodos en que políticamente el proyecto de nación se definiría esencialmente como un proyecto modernizador.

Samuel Ramos, Leopoldo Zea, Antonio Caso, José Vasconcelos, Octavio Paz, Carlos Fuentes, Carlos Monsiváis, son algunos de los pensadores que desde distintos ámbitos, particularmente el de la filosofía, han debatido el tema de la identidad nacional. Sin embargo, quizás sea Roger Bartra quien mejor nos sirva a propósito de indicar que el debate sobre la identidad nacional y la creación de los mitos nacionales, no hace sino reflejar ese reacomodo social que se da en presencia de la modernidad, cuando adaptando las ideas de Clausewitz, el gran táctico militar del siglo XIX, dice:

Los mitos nacionales no son un reflejo de las condiciones en que vive la masa del pueblo ni una diversión falsa (ideológica) de la conciencia. Más bien, "como parte de la cultura son, digamos, la prolongación de los conflictos sociales por otros medios". ${ }^{14}$

Existe, por un lado, ese proceso continuo que significa día con día "hacer la mexicanidad"; pero de la misma manera existe la necesidad de la formación del mito de la mexicanidad, como correlato político de una idea de nación,

13. Flores Olea, Víctor (1993), "Identidad nacional. Los rostros en movimiento", en La Jornada Semanal, núm. 186, 3 de enero.

14. Bartra, Roger (1987), La jaula de la melancolia: identidad y metamorfosis del mexicano, Grijalbo, p. 238; citado también por Gutmann, Matthew C. (1993), en "Culturas primordiales y creatividad en los orígenes de lo mexicano", en La Jornada Semanal, núm. 186, 3 de enero, p. 36. 
creada para satisfacer el discurso de la unicidad social necesario en todo proceso de modernidad.

Es evidente también que existen muchos Méxicos, y que somos un país plural en donde cohabitan modos de cultura distintos. No obstante, hay una pugna por definir y proteger nuestra identidad cultural en presencia de la redefinición de nuevos proyectos de nación, o de la formación de una nueva identidad nacional. De manera que, así como siguiendo a Touraine nos detuvimos a separar el concepto de modernidad del de su correlato de modernización, de la misma manera analítica es preciso distinguir las particularidades de la noción de "identidad cultural", de las características integradoras que el Estado propone como parte de una identidad nacional.

Esta precisión conceptual nos prueba ser de gran utilidad, en la medida en que nos posibilita aclarar el debate teórico que se ha venido dando en torno al tema de la identidad:

Quienes en su momento, ante la firma del TLC, hablaron de la necesidad de preservar una identidad para nuestro país, confundían los términos, ya que observaban en la fusión un peligro para nuestra identidad cultural, cuando en realidad estaban llevando a cabo una furiosa defensa de la identidad nacional. ${ }^{15}$ Quienes defendían la integración, generalmente lo hacían sobre la base de aclarar que toda cultura necesita revitalizarse por contacto con otras, ya que aquella cultura que no permite la inclusión de elementos nuevos, aun pertenecientes a otras culturas, perece; de esta forma estaban esencialmente refiriéndose a lo que aquí hemos dado en llamar precisamente identidad cultural. ${ }^{16}$

Remitiéndonos nuevamente a la noción de cultura como alimento esencial de nuestros pueblos, y a la emisión continua de productos de cultura, sostenemos que estamos en presencia de una identidad cultural viva y cambiante. Yo creo que nadie que haya observado la evolución de México durante los últimos diez años podrá negar que nuestra identidad cultural no ha sido eclipsada ni erradicada por nuestra relación con nuestros socios comerciales. Lo que sí es importante señalar es que lo que ha cambiado es nuestra identidad nacional, simplemente porque lo que se ha transformado es nuestro proyecto de nación.

15. Carlos Monsiváis, por ejemplo, ha hecho en repetidas ocasiones una importante crítica a las formas de fusión de la identidad del mexicano con otras influencias, particularmente la estadounidense, al punto de decir que ya tenemos aquí "la primera generación de estadounidenses nacidos en México".

16. Al respecto es factible ver la obra del antropólogo Néstor García Canclini, o bien las ideas manifestadas por el escritor Carlos Fuentes, quienes vieron en su momento, en la implementación de un Tratado de Libre Comercio para México, la posibilidad de un crecimiento cultural. 
Volteemos la mirada ahora a los proyectos de nación que nuestro país ha instrumentado a lo largo de las diferentes vidas de su sistema político, parte como elemento unificador de los discursos, y parte como elemento constructor de un imaginario social de progreso y modernización, y estaremos en presencia de nuestra identidad nacional. Descubramos ahora los nexos que vinculan una y otra concepción, fundiéndolas a veces en una sola, y apuntaremos a destacar uno de los mecanismos modernizadores más importantes en operación: el de la construcción de los discursos de la modernidad a través de los medios de comunicación colectiva.

Esos proyectos de nación se han transformado simplemente porque hace diez años la discusión política en torno de si entrar o no al TLC se centraba sobre el tema de la soberanía. Hoy ya nadie se preocupa de la soberanía; nuestra relación con Estados Unidos y Canadá es un hecho y estamos más que preocupados porque dicha relación se lleve en buenos términos. Sabemos que con nuestras economías ligadas, hoy más que nunca es importante conseguir el aval económico y político de Estados Unidos.

Lo que sí se cuestiona es nuestra nacionalidad, nuestro amor por la patria.

Los partidos de oposición al partido en el poder le reprochan haberle dado la espalda al proyecto revolucionario y pretender modificar las estructuras legales y de la administración pública para mantener el proyecto económico. En el trasfondo, sin embargo, coexiste una identidad cultural cambiante, con una identidad nacional que se quedó anclada en un sistema político, en un régimen y en una estructura de partido que ya no corresponde a la realidad actual.

Quienes todavía apuntan hacia el problema de la identidad en cualquiera de sus dos acepciones, sea cultural o nacional, quizás se quedan cortos al señalar sólo una parte del problema; el análisis debiera centrarse en las formas en las que estructuralmente se están entrelazando los mecanismos culturales con los mecanismos de cooptación política y económica. Quizás la discusión debiera centrarse más en términos de la discusión de un proyecto nacional, que aglutina en sus propuestas la premisa inherente de una fusión cultural característica de una modernización esencialmente económica; y claro, frente a las protestas de algunos sectores intelectuales ante las propuestas de ese proyecto modernizador, en la manifestación clara, una vez más, de una preocupación no tanto cultural sino política, relativa a la ausencia de participación social en la definición de un proyecto modernizador nacional.

Si revisamos el proceso de creación de identidad nacional por el que atraviesa nuestro país, y la participación del Estado contemporáneo en la creación de semejante identidad, podemos establecer cinco etapas fundamentales, según Carlos Monsiváis: en la primera (1910-1920), los cambios que se dan no significan el fin de un sistema económico, pero denuncian las presiones de una revolución social y cultural en torno al nuevo trato del individuo con 
la Nación; en la segunda (1920-1940), el Estado decide convertir el nacionalismo en la educación cívica y moral de las mayorías a través del desarrollo de una mitología posrevolucionaria, que es el método unificador sin el cual no procede la modernización; en la tercera, (1940-1960), el elemento importante es la campaña de la unidad nacional que permite la industrialización acelerada que faculta al desarrollo nacional (para arribar al progreso sólo se requiere unirse con firmeza en torno a la nación-Estado). En la siguiente etapa (19601980 ) se agudizan las presiones de la modernización sobre el nacionalismo, sin embargo, apoyado en el culto fanático a la tecnología, se solidifica el poder del Estado, se extiende la cultura urbana, se aceptan un conjunto de mitos y costumbres internacionales debido, en gran medida, a la presencia de los medios de comunicación masiva. Y por último, en la quinta etapa, "la de la crisis" (1980 a la fecha), el nacionalismo se enfrenta primero al reclamo de una democratización violenta de la vida nacional que comienza a manifestarse desde 1985, y que se torna en un nacionalismo exacerbado porque "en el fondo nunca creyó en las alternativas" (Monsiváis, 1987: 13-22).

El análisis anterior es generado por Monsiváis antes de las elecciones de 1988, cuando el Estado mexicano no reconvertía todavía los rastros de un nacionalismo resucitado, pero si nosotros extrapoláramos su planteamiento a la realidad actual, tal vez podríamos acotar que en esta última etapa el nacionalismo mexicano se ha eclipsado en aras de una identidad postnacional que no reconoce fronteras culturales, sino que se funde con las otras identidades: las del consumo, las de la tecnología, la de la globalización.

Es ésta quizás el tipo de identidad posnacional a la que se refería Roger Bartra cuando decía que, para países como el nuestro, la problemática consiste en la superación democrática del autoritarismo, aunado al atraso económico, lo cual implica el problema de superar el orgullo nacionalista para construir una identidad posnacional, basada en las formas pluriculturales y democráticas de una vida cívica que forme parte del mundo occidental. Para Bartra (1991: 17-19), la modernidad, junto con el nacionalismo, está herida de muerte y no tenemos más remedio que enfrentar a la posmodernidad del fragmentado mundo occidental del que formamos parte.

Ahora bien, lo que Bartra supone es que el avance de nuestra identidad cultural marcha a la par del avance de nuestra identidad nacional. Si bien en la arena cultural hemos incluso desarrollado procesos culturales de adopción, asimilación e hibridización de las culturas, en el aspecto político, la transición hacia una cultura política postnacional que dé paso a una rica y democrática multiplicidad, se enfrenta tòdavía a crisis de gobernabilidad y legitimación del sistema. Sobre esto último, recordemos además las palabras de Carlos Fuentes al decir que, es cierto, nuestro país tiene que reanudar un desarrollo económico, pero éste ya no puede privarse de su escudo político que es la democracia; ni de su escudo social que es la justicia; ni de su escudo mental 
que es la cultura. En este último caso la cultura actúa como elemento de adhesión e identificación de la identidad, pero sólo en la medida en que su variedad sea respetada y pueda manifestarse libremente (Fuentes, 1991a, 15).

Fuentes (1992: 29) apunta que la modernidad ha sido nuestro fantasma constante, nos ha acompañado a lo largo de toda nuestra historia. La realidad, dice el autor, es que tenemos que hacer cuentas con nuestro pasado para enfrentarnos a esa historia y asumir lo que somos. Mientras no asumamos lo que somos no podremos seguir adelante. Ahora bien, parte del reconocimiento de la propia identidad estriba en el reconocimiento del otro, en la conciencia de lo extraño, que acaba por enriquecernos.

La problemática de la apropiación intercultural en nuestro tiempo, radica en la aceleración de los procesos que resultan de la nueva tecnología de información, y particularmente en un momento como el actual, en que las identidades son políglotas, multiétnicas, migrantes y hechas con elementos de varias culturas, cuando por primera vez (en este nuevo siglo), la mayor parte de los bienes y mensajes que recibimos no son producidos en el propio territorio, ni llevan vínculos que los liguen a la comunidad nacional, sino que más bien pertenecen a un sistema desterritorializado (García Canclini, 1992: 32-33).

Ahora bien, en una situación de interculturalidad como ésta, las culturas se configuran no sólo por las diferencias entre culturas desarrolladas de manera desigual, sino por las maneras desiguales en que los grupos se apropian de elementos de varias sociedades, los combinan y los transforman. El objeto de estudio de una situación tan particular como la que ahora se nos presenta, dice García Canclini (1992: 34), debe ser no sólo la diferencia, sino
también la hibridación.

Otro antropólogo, Guillermo Bonfil Batalla, en uno de sus últimos trabajos, apuntaba directamente sobre las consecuencias culturales del Tratado de Libre Comercio para nuestro país; en dicha intervención decía:

En el terreno cultural, en efecto, una de las posibilidades más sugerentes y positivas del TLC sería la de facilitar la circulación más libre de ideas y de los valores alternativos que éstas conllevan. Por decirlo en términos telecistas: una oferta mayor y más divertida de ideas y valores capaces de dar sentido a nuestra existencia [...] El problema no está en el TLC [...] sino en los mecanismos sociales y políticos que seamos capaces de instrumentar en la sociedad mexicana para asegurar el mejor uso posible de esa prerrogativa en beneficio auténtico de 17. Bonfil Batalla, Guillermo (1991), “Dimensiones culturales del Tratado de Libre Comer-
cio”, en México Indigena, núm. 24, septiembre, p. 10. 
Considero que si Bonfil Batalla pudiera ver a nuestro país se daría cuenta de que en estos momentos la sociedad mexicana del siglo XXI se ha convertido en una gran torre de Babel. Efectivamente, la apertura económica y la transición democrática trajeron como resultado la circulación irrestricta de las ideas, pero no hemos llegado al punto en que la discusión sensible de esas ideas nos permita el autorreconocimiento como sociedad plural, la aceptación de la diversidad en los valores y sobre todo, la posibilidad de los consensos.

Bonfil Batalla se preguntaba hasta qué punto la identidad nacional, forjada en nuestro pueblo a resultas de la Revolución mexicana, sedimentará en nuestra cultura una idea específica de soberanía nacional, y de qué manera el proyecto nacional que se perfilaba, modificaría totalmente ese sustrato cultural. Decía Bonfil Batalla:

La apertura del mercado, que ya es un hecho consumado con o sin TLC, tiene implicaciones culturales de gran trascendencia. La opción de promover una oferta cada vez mayor de productos y más variados es, en el fondo, la opción por un cierto modelo de vida: solamente uno, particular y único, entre otros muchos posibles. En el contexto actual, ese modelo es el de una sociedad de consumo, que valora la adquisición, la acumulación y la renovación de bienes como el propósito más alto de la existencia social e individual. En una sociedad como la nuestra, en el futuro previsible, este modelo producirá, además, mayor desigualdad: una concertación más alta y una marginación más extendida [...] No es un problema que se limite a borrar barreras arancelarias: va mucho más allá porque implica asumir un modelo de sociedad para el futuro. Ese modelo, ilo estamos adoptando libre y soberanamente los mexicanos? ¿Nos es impuesto por la fuerza de las cosas, por las leyes ineluctables de la historia, por un destino indiscutiblemente manifiesto al que sólo cabe someterse fatalmente? ${ }^{18}$

Quizás lo que finalmente sucedió no fue tanto que éste fuera un modelo adoptado libre y soberanamente por los ciudadanos de una nación, sino que ya existía de tiempo atrás en nosotros el germen de toda sociedad moderna en gestación. Lo único que sucedió es que ansiaba el momento propicio para reproducirse, posibilitando así la coexistencia cultural de elementos tradicionales, junto con los productos masivos del consumo cultural.

Tal y como sugiere Edgar Morin, las sociedades modernas son "policulturales" en el sentido de que agrupan en su seno tanto los fenómenos culturales del consumo masivo, como elementos de la cultura nacional, de tal manera que la resultante acaba siendo una cultura "cosmopolita por vocación y planetaria por extensión"; o dicho de otra manera, una cultura producto de una dialéctica producción-consumo en el seno de una dialéctica global de

18. Bonfil Batalla, Guillermo (1991), "Dimensiones culturales del Tratado de Libre Comercio", op. cit., p. 18. 
industrialización planetaria. ${ }^{19}$ Dicha industrialización planetaria es el inevitable punto de llegada de toda sociedad moderna; es la meta de todo proceso de modernización, el momento mismo de la posmodernidad como instante creador excelso de todo lo moderno. Se ha sugerido aquí, sin embargo, que las metas no se alcanzan en la misma proporción, en todos los ámbitos y en todos los casos: en el caso de México, los procesos de modernización económica nos llevaron a alcanzar una modernidad autoritaria, impuesta como proyecto nacional; mientras que la modernización cultural, que es un hecho consumado, se perfila hacia la posmodernidad.

Esta paradoja de desarrollos desiguales pero compartidos, se aclara cuando tomamos precisamente el concepto de hibridización intercultural de García Canclini, y cuando se siente, desde la óptica de Bonfil Batalla, que aunque la lógica modernizadora funcione igualmente desde la perspectiva económica y desde la perspectiva cultural, al interior de nuestro país, los procesos de modernización y culturización dan cuenta ya de fenómenos de hibridización adyacentes. El analfabetismo subsiste mientras que el país se encamina hacia su transformación en eMéxico. Dicho de otra manera: observamos la coexistencia de acercamientos paralelos de diversos sectores, pero con distintos grados de avance a la modernidad. El análisis de la desigualdad de García Canclini nos aclara la manera como estos distintos grados de modernidad pueden coexistir al interior sociedades, en donde la presencia de elementos tradicionales con elementos modernos ha producido interesantes procesos de hibridización.

Los medios de comunicación juegan un importante papel en este proceso, ya que entre otras cosas, la redistribución masiva de los bienes simbólicos tradicionales por los canales electrónicos de comunicación genera interacciones más fluidas entre lo culto y lo popular, lo tradicional y lo moderno (García Canclini, 1990: 183).

García Canclini indica que, tomando como base la perseverancia y los reacomodos de tantas costumbres y formas de pensamiento luego de 500 años de cambios, primero por la dominación colonial y luego por los varios proyectos de modernización, el Tratado de Libre Comercio no borraría la identidad cultural de nuestro país (García Canclini, 1992: 25). No obstante, también apuntó en su momento que era necesario considerar cuidadosamente las asimetrías y dominaciones que a menudo regulan los vínculos interculturales, para lo cual sugería observar muy de cerca los circuitos de desarrollo cultural, entre los que se encuentran en forma determinante los medios de comunicación, ya que la cultura nacional depende en gran medida de las transformaciones que se den en estas importantes áreas de influencia. El autor aclaraba que

19. Véase el pensamiento de Edgar Morín, en sus obras El espíritu del tiempo I (1962) y El espíritu del tiempo II (1962). 
si bien nuestra identidad cultural ha soportado importantes embestidas, si no se desarrollan políticas nacionales en las comunicaciones masivas y en relación con las tecnologías existentes de información y comunicación, la capacidad de sostener aspectos claves de la identidad y un desarrollo autogenerado, disminuirán velozmente (García Canclini, 1992: 37). Pues bien, los medios de comunicación también han sufrido cambios importantes como resultado de la modernización económica y la apertura democrática; nuevos actores sociales han entrado a la esfera de la comunicación a participar como agentes transmisores del discurso. Los circuitos culturales han cambiado. Ya no existe un discurso unitario que soporte al sistema y al régimen político como en décadas anteriores, ahora la sociedad mexicana tiene acceso a una variedad de discursos pero, en términos generales, no es capaz todavía de generar sus propios circuitos de expresión cultural.

¿Será que nuestra identidad cultural representa el último reducto contra la globalización? iSerá que como parte de nuestra entrada a la modernidad tuvimos que asumir procesos de hibridización permanentes que terminarán por difuminar nuestros rasgos culturales bajo la sombra de una supuesta identidad posnacional?

\section{Medios de comunicación, globalización e imaginario social}

Lo que resulta evidente del planteamiento anterior, es la necesidad de revisar cuidadosamente el papel desempeñado por los medios de comunicación en todo el proceso, ya que la acción de los medios de comunicación es vista, en sí misma, como ejemplo vivo y actuante de la modernidad.

La capacidad informativa de las nuevas tecnologías, la simultaneidad en la que aparecen los discursos, la globalización instantánea que permite a un mismo mensaje recorrer al mundo en cuestión de segundos... Todo ello representa la faceta encandiladora de la modernidad. De hecho, la simultaneidad de la comunicación se ubica en el centro mismo del fenómeno de la modernidad, y lo que es más, la vigencia en la unicidad de los discursos nos lanza violentamente hacia las posibilidades de una posmodernidad en acto, que es, en esencia, el instante creador de la modernidad. Lo anterior permite conducir a la sociedad, a una sociedad en donde la comunicación es ilimitada, o como también se le conoce, a una "sociedad transparente" (Vattimmo, 1990), término a través del cual quieren ponerse de manifiesto la pluralidad de los mecanismos y armazones internos con los que se construye la cultura.

Ahora bien, simultáneamente a los fenómenos de discusión, análisis y recrudecimiento del debate sobre las identidades nacionales y culturales, y 
junto con los procesos de resistencia cultural, se están dando procesos en los cuales las expresiones culturales propias de los pueblos parecen diluirse en el remolino de la instantaneidad o la "transparencia" de la información; en donde acercándonos al momento sublime de la posmodernidad, el sujeto social, en contacto con la información del momento, puede estar con otros sujetos a miles de kilómetros de distancia, todos alejados de una idea única de nación o de cultura, y en donde las distintas manifestaciones y perfiles de la cultura se encuentran en una sola expresión tecnológica universal: la de la instantaneidad de la comunicación.

Bonfil Batalla indicaba que ante un fenómeno como éste, en donde se observa la globalización no sólo de las comunicaciones, de los mercados, de los capitales y de la tecnología, las decisiones que cuentan se toman en otra esfera, es decir en aquella en la que pesan más los intereses trasnacionales. Los Estados nacionales tienden a formar bloques, nuevas alianzas para ocupar una parcela en la economía global. El mundo se achica, la comunicación instantánea no respeta fronteras (Bonfil Batalla, 1990: 15). Y así, entonces, la dinámica de la política es otra. La modernidad acerca al sujeto a la idea de nación; la posmodernidad lo funde con la aldea global y lo nutre con la posibilidad de una identidad social universal, posnacional.

Resulta pertinente apuntar, sin embargo, que pese al eterno reclamo de grupos sociales e intelectuales diversos acerca de las transformaciones de las identidades en la era de la globalidad, en general la respuesta es que las identidades locales o regionales no se encuentran amenazadas frente a la promesa de una identidad universal o posnacional.

Ese mismo argumento se esgrimió al principio de la negociación trilateral para el Tratado de Libre Comercio de América del Norte, cuando mientras Canadá claramente apuntaba que se oponía a incluir a sus industrias culturales en las negociaciones del TLC, ya que dicha área era considerada "una parte vital de la conservación de nuestra identidad cultural", ${ }^{20}$ Estados Unidos, por su parte, declaraba que "si Canadá insiste en la exclusión de las industrias culturales, entonces debe modificarse el tratado tripartita y firmarse un acuerdo sólo con México". ${ }^{21}$ En nuestro país, el secretario de Comercio y Fomento Industrial y jefe del equipo negociador en ese entonces, Jaime Serra Puche, expresaba en controvertida declaración que: "Respecto de la cultura, es un asunto que no es tan relevante para México".22

20. "Se opone Canadá a incluir su industria cultural en el TLC", en Unomásuno, 17 de mayo, 1991.

21. "Estados Unidos no aceptará que se excluya el tema de cultura del TLC", en La Jornada, 13 de julio, 1991.

22. Conferencia de prensa del 12 de junio de 1991, comentada en diversos diarios nacionales. 
Años más tarde, ya bien entrada la transición democrática, el gobierno del Presidente Zedillo le estaría heredando al Presidente Fox el problema del reconocimiento de la autonomía de los pueblos indígenas en Chiapas, situación que todavía no se resuelve porque la transformación de lo político lleva una lógica y unos tiempos totalmente diferentes a los de las demandas culturales de nuestras etnias.

No bastaron aquí los discursos mediáticos ni los discursos políticos proyectados a través de las empresas de medios, para sosegar a un país que tenía enfrente las contradicciones cada vez más evidentes de una modernización económica impuesta por sobre las estructuras premodernas de la política y las manifestaciones posmodernas de los medios.

Ni siquiera bastó incorporar al discurso político el mensaje de la importancia de nuestra diversidad cultural a través de otras instancias productoras de cultura, como las escuelas, los museos, los espectáculos, etc., que de hecho contribuyen enormemente, junto con los medios de comunicación, a crear el imaginario social apropiado a la modernidad. De todas maneras fueron evidentes las asimetrías, pero ya no entre los socios comerciales del TLC sino entre los propios grupos y actores políticos y sociales que coexisten en el México del siglo XXI.

Como indica Javier Esteinou (1992: 36):

Existe la necesidad inminente de reflexionar sobre nuestra cultura y la acción que deben ejercer los medios de comunicación, para conservar su esencia nacional orientada hacia el desarrollo de nuestra conciencia dentro de la dinámica de acelerado cambio modernizador que vive el país; pues el proceso de la globalización mundial nos lleva a la creación de un nuevo orden cultural que modificará los contenidos y las fronteras ideológicas de los actuales estados nacionales. De lo contrario, el alma cultural de nuestra sociedad correrá el gran riesgo de quedar sepultada por los nuevos espejismos de la modernidad y sus derivados simbólicos parasitarios de esta nueva fase del desarrollo de la sociedad capitalista internacional.

Por otra parte, es notable cómo día a día los medios de comunicación gestan un imaginario social proclive a la modernización y a los mecanismos de la globalización económica. Nuestra niñez y juventud se ven sometidas a las atractivas ofertas del mercado capitalista, por un lado, y por otro, a los reclamos naturales de su identidad nacional. Esto ha provocado una enorme contradicción entre la sensibilidad que el Estado mexicano siembra por la mañana en las conciencias de los niños, jóvenes y adultos, con muchísimos esfuerzos, a través de la educación formal, y que se destruye por la tarde y noche mediante la acción des-educativa de los avanzados canales de comunicación, particularmente la televisión (Esteinou, 1991: 16-17). 
¿Es ésta acaso una reacción natural, producto de la esquizofrenia que nos lanza la modernidad, cuando simultáneamente al desear obtener las maravillas que nos promete la modernidad, nos encarnamos en la identidad otra, en la extraña, en la posnacional, para sentirnos ubicuos, integrados a la información planetaria, mientras que, paralelamente, defendemos con uñas y dientes los últimos resquicios de nuestra identidad?

No hay que olvidar que aquí hemos propuesto una distinción básica entre dos conceptos de identidad: por un lado, la identidad nacional, misma que está sujeta a cambios, puesto que proviene de los proyectos de nación planteados por el Estado; y por otro lado, la identidad cultural que es dinámica y cambiante, por lo que permanentemente adopta, adapta, excluye, incorpora y modifica elementos culturales diversos en un continuo proceso de hibridización. ¿Cuál de estas identidades es la que nos guía en el México moderno de la transición democrática? ¿Será que una cobra preeminencia sobre la otra? Pareciera ser que la segunda, la identidad cultural, constituye nuestra única posibilidad real de escapar al caos, a la ausencia de proyecto nacional, ya que se desdobla y se rearticula para permitir la incorporación de nuevos elementos culturales, pero sin dejar de sostener una permanente resistencia, hacia los mecanismos impuestos por los proyectos nacionales, que ahorcan la esencia cultural de cada uno de los pueblos.

México no va a dejar de ser lo que es; quizás Carlos Fuentes tenía razón cuando decía:

La identidad nacional mexicana es muy fuerte, más que la estadounidense. Son ellos los que deben temernos, la lengua castellana, la continuidad cultural y la pluralidad de tradiciones (indígena, española, mestiza, mediterránea) acentuarán el mestizaje estadounidense. Para nosotros la policultura no es un problema. ${ }^{23}$

Sin embargo, también es un hecho que ante la influencia intercultural nuestro país no quedaría incólume, su identidad cultural continuará recomponiéndose en presencia de elementos culturales ajenos, ante los cuales se adopta una mecánica de imitación conjunta a procesos de resistencia; el resultado: la hibridización cultural de la que habla García Canclini.

Ahora bien, qué tanto esta nueva recompuesta identidad cultural responderá al proyecto de nación y a la figura de identidad nacional que el moderno Estado mexicano plantea para todos nosotros, está por verse.

Lo más probable es que ambas identidades, la nacional y la cultural, se combinen para formar parte del imaginario social al que todos contribuimos y del que todos nos alimentamos culturalmente. ¿Cómo discernir, en medio

23. Fuentes, Carlos (1991), "El TLC no afectará nuestra identidad nacional”, en La Jornada, 18 de julio. 
de esos cruces de identidades, qué es lo propio de la cultura de un pueblo, y qué es lo que ha sido generado por las tecnologías comunicacionales? La cuestión aquí radica, entonces, en determinar qué elementos culturales y provenientes de qué orígenes, son los que mayoritariamente participan, qué sujetos, qué actores sociales y políticos, son los que operan en la conformación de esos discursos.

El momento coyuntural que vive nuestro país sintetiza el ejercicio de muchas fuerzas que se vienen gestando desde nuestra supuesta constitución como país moderno; sin embargo, es en este siglo que habrá una recomposición de los imaginarios sociales cuyos orígenes habrán sido los valores de identidad nacional y cultural.

Los medios de comunicación desempeñan un papel preponderante en la construcción de dichos imaginarios sociales y en la generación de una base flexible de sustento político; así lo reconocieron en su momento ciertos miembros claves de la clase política, quienes, como Ruiz Massieu, voltearon sus ojos hacia estos interlocutores tecnológicos, con miras a determinar los espacios que habrían de ocupar en las próximas décadas:

Con los medios colectivos de comunicación, el nuevo entendimiento no podrá ignorar que son una expresión del pluralismo social, y con cautela tendría que hacerse frente a las relaciones económicas entre ellos, el Estado y otros poderes; y entre los medios y los propios periodistas.

Con Estados Unidos el entendimiento, es seguro, oscilará entre la vinculación eficiente de México en el mercado norteamericano, que sirva mejor a nuestro desarrollo y a la soberanía y pondere las tendencias multipolares; el respeto puntual a la independencia y la protección eficaz de los intereses mexicanos. $^{24}$

Si Ruiz Massieu tenía razón y el partido en el poder reconocía la importancia de la labor de los medios de comunicación para el proyecto de modernización del país, no es gratuito pensar que los medios de comunicación tendrán un papel preponderante en la reconstrucción política del México postmoderno.

Una forma de aproximarse al fenómeno que estamos viviendo, consiste en construir un criterio de lo rescatable - más que por oposición entre lo tradicional y lo moderno-, por distinción entre lo arcaico, lo residual y lo emergente; siendo lo arcaico lo que pertenece al pasado y es conocido como tal por quienes hoy lo reviven; lo residual, lo que se formó en el pasado, pero que todavía se halla en actividad dentro de los procesos culturales, y lo emergente, que designa los significados y valores, nuevas prácticas y relaciones sociales

24. Ruiz Massieu, José Francisco (1990), op. cit., p. 55. 
(Williams, en García Canclini, 1990: 184). Es evidente que el país no puede avanzar hacia una transformación profunda si no se asume que estos elementos coexisten en nuestras identidades profundas, y que ningún proyecto nacional es posible sin el reconocimiento de las expresiones identitarias cambiantes de todos los actores políticos y sociales.

Sólo de esta forma es que podríamos intentar un análisis a fondo, que nos permitiera ver de cerca nuestra identidad cultural, para diferenciarla claramente de la identidad nacional y de las otras identidades que nos propone el proyecto de transformación política y económica que encara el nuevo régimen.

No es propósito de este trabajo delimitar los alcances de la transformación de nuestro país; sentimos que todavía nos hacen falta muchos elementos para poder siquiera atisbar el complejo panorama que tenemos por delante; sin embargo, lo que sí nos queda claro es la importancia de la intersección entre los ejes modernidad, identidad y modernización para México, así como la certeza de que vale la pena continuar desentrañando sus posibles cruces, con la esperanza de lograr en el proceso una mayor claridad para el camino.

Es cierto que cerrar los ojos a la globalización sería detener nuestro desarrollo, nos condenaría al aislacionismo y al anquilosamiento; sin embargo, viendo en retrospectiva este proceso económico y político y sus efectos para México durante la última parte del siglo XX, podemos observar que al zambullirnos tan de golpe en el océano de la modernidad, probablemente perdimos de vista la otra orilla. Nos dejamos envolver por el discurso de la globalidad olvidando los espacios de nuestra vida cotidiana, y permitimos que paulatinamente se desplazara nuestra "cultura de lo real" (la que se sustenta en las circunstancias de la sociedad en la que se vive y a la que se pertenece), sustituyéndola por una "cultura imaginaria" construida a partir de la aspiración de "cambiar la realidad".

\section{Bibliografia}

Bartra, Roger (1987), La jaula de la melancolia: identidad y metamorfosis del mexicano, Grijalbo.

Bartra, Roger (1991), "La venganza de la Malinche: hacia una identidad postnacional", en Este Pais, abril.

Bonfil Batalla, Guillermo (1991), Pensar nuestra cultura, Alianza Editorial (1991), "Dimensiones culturales del Tratado de Libre Comercio", en México Indígena, núm. 24, septiembre. 
Brunner, José Joaquín (1990), "Tradicionalismo y modernidad en la cultura latinoamericana", documentos de trabajo FLACSO, Santiago de Chile, serie Educación y Cultura, núm. 4.

(1992), "América Latina en la encrucijada de la modernidad", en Comunicación, identidad e integración latinoamericana. En torno a la identidad latinoamericana, vol. I, memorias del VII Encuentro Latinoamericano de Facultades de Comunicación Social.

Camou, Antonio (1992), “Once notas sobre la 'transición mexicana'. Gobernabilidad y democracia”, en Nexos, núm. 170.

Casullo, Nicolás (comp.) (1989), El debate modernidad-posmodernidad, Editorial Puntosur.

Constantino Toto, Mario (2000), "Participación ciudadana", en Bokser Liwerant, Judit (coord.), Léxico de la politica, FCE.

Cruz, Alejandro (2001), "Los cambios del cambio", en Nexos, julio.

Esteinou, Javier (1991), "La televisión mexicana ante el modelo de desarrollo neoliberal”, Fundación Manuel Buendía, Programa Cultural de las Fronteras.

Esteinou, Javier (1992), "Hacia el fast track de la desnacionalización mental. Comunicación y cultura social en el neoliberalismo", en Revista Mexicana de Comunicación, año 5, núm. 26, noviembre-diciembre.

Fernández Reyes, Otto (1993), "El dilema de la modernidad”, en el suplemento especial de política El Nacional, 28 de enero.

Flores Olea, Víctor (1993), "Identidad nacional. Los rostros en movimiento", en La Jornada Semanal, núm. 186. 3 de enero.

Fuentes, Carlos (1990), Valiente mundo nuevo, Fondo de Cultura Económica.

Fuentes, Carlos (1991), “Nacionalismo e integración”, en Este País, abril.

Fuentes, Carlos (1991), “El TLC no afectará nuestra identidad nacional”, en La Jornada, 18 de julio.

Fuentes, Carlos (1992), “La pasión del futuro", en Nexos, núm. 175, julio. García Canclini, Néstor (1990), Culturas híbridas. Estrategias para entrar y salir de la modernidad, Grijalbo, Conaculta.

García Canclini, Néstor (1992), "Museos, aeropuertos y ventas de garage. La cultura ante el Tratado de Libre Comercio", en La Jornada Semanal.

Gilly, Adolfo (1988), "La otra modernidad”, en Nexos núm. 124, abril.

Gutmann, Matthew (1993), "Culturas primordiales y creatividad en los orígenes de lo mexicano", en La Jornada Semanal, núm. 186, 3 de enero.

La Jornada (1991), "Estados Unidos no aceptará que se excluya el tema de cultura del TLC", 13 de julio. 
Monsiváis, Carlos (1987), "Muerte y resurrección del nacionalismo mexicano", en Nexos, núm. 109, enero.

Paz, Octavio (1967), Corriente alterna, Siglo XXI.

Ruiz Massieu, José Francisco (1990), Ideas a tiempo, Editorial Diana.

Secofi (1993), Tratado de Libre Comercio de América del Norte, tomo I.

Sinclair, Jim (ed.) (1992), Canada and Free Trade with Mexico. Crossing the Line, New Star Books, Vancouver.

Touraine, Alain (1990), "Modernidad y especificidades culturales", en Vertientes de la modernización, CEN, PRI.

Unomásuno (1991), "Se opone Canadá a incluir su industria cultural en el TLC", 17 de mayo.

Vattimmo, Gianni (1990), La sociedad transparente, Paidós. 